\title{
Análise bacteriológica da água em bebedouros de escolas municipais de Feira de Santana/BA
}

Bacteriological analysis of water in municipal schools of Feira of Santana/BA

Análisis bacteriológico del agua en los abrevaderos de las escuelas municipales de Feira de Santana/BA

Recebido: 07/01/2021 | Revisado: 08/01/2021 | Aceito: 16/01/2021 | Publicado: 19/01/2021

Carolina Ferreira Amorim

ORCID: https://orcid.org/0000-0003-1538-6762

Universidade Federal da Bahia, Brasil

E-mail: cfa.biomed@gmail.com

Ana Carolina Santana de Oliveira

ORCID: https://orcid.org/0000-0001-8335-2359

Unidade de Ensino Superior de Feira de Santana, Brasil

E-mail: anasantanoli@yahoo.com

Rodrigo Almeida Martins

ORCID: https://orcid.org/0000-0001-9063-0062 Unidade de Ensino Superior de Feira de Santana, Brasil E-mail: almeidamartino@gmail.com

Carolayne Araújo de Oliveira Freitas

ORCID: https://orcid.org/0000-0002-1319-5228

Unidade de Ensino Superior de Feira de Santana, Brasil

E-mail: caroolfreitas55@gmail.com

\begin{abstract}
Resumo
A pesquisa teve como objetivo avaliar se a água em bebedouros de escolas da rede municipal em três bairros de Feira de Santana/BA seguia os parâmetros para ausência de coliformes. As amostras foram analisadas em duplicata contemplando 16 escolas, onde as coletas de água eram feitas diretamente nos bebedouros após a assepsia com álcool $70 \%$ em frasco de vidro com tiossulfato de sódio a $10 \%$ sendo avaliadas no período igual a 24 horas. A técnica usada para identificação de coliformes totais e termotolerantes foi à de Tubos Múltiplos, na qual as amostras que apresentaram coliformes seguiram para realização das provas bioquímicas para identificação da espécie isolada. Dentre as escolas avaliadas 37,5\% detectaram coliformes totais e 62,5\% não apresentaram este agente entérico. Conclui-se que parte das escolas participantes desta pesquisa não segue os padrões de potabilidade de água estabelecidos pela Portaria de Consolidação n ${ }^{\circ} 5$ de 28 de setembro de 2017.
\end{abstract}

Palavras-chave: Padrão de potabilidade de água; Coliformes; Bebedouro.

\begin{abstract}
The research aimed to evaluate if the water in drinking fountains of municipal schools in three neighborhoods of Feira de Santana/BA followed the parameters for coliform absence. The samples were analyzed in duplicate contemplating 16 schools, where the water was collected directly in the troughs after asepsis with $70 \%$ alcohol in a glass jar with $10 \%$ sodium thiosulfate being evaluated in the period equal to 24 hours. The technique used for the identification of total coliforms and thermotolerant was that of Multiple Tubes, in which the samples that presented coliforms followed to perform the biochemical tests to identify the isolated species. Among the schools evaluated $37.5 \%$ detected total coliforms and $62.5 \%$ did not present this enteric agent. It is concluded that part of the schools participating in this survey do not follow the standards of water potability established by the Consolidation Ordinance ${ }^{\circ}$ of september 28 , 2017.
\end{abstract}

Keywords: Water potability standard; Coliforms; Drinker.

\section{Resumen}

El objetivo de la investigación fue evaluar si el agua de las fuentes de las escuelas municipales de tres barrios de Feira de Santana/BA seguía los parámetros de ausencia de coliformes. Las muestras se analizaron por duplicado contemplando 16 escuelas, donde el agua se recogió directamente en los bebederos después de la asepsia con un $70 \%$ de alcohol en un frasco de vidrio con un $10 \%$ de tiosulfato de sodio que se evaluó en el período igual a 24 horas. La técnica utilizada para la identificación de coliformes totales y termotolerantes fue la de Tubos Múltiples, en la que las muestras que presentaban coliformes se siguieron para realizar las pruebas bioquímicas para identificar las especies aisladas. Entre las escuelas evaluadas, el 37,5\% detectó coliformes totales y el 62,5\% no presentó este agente entérico. 
Se concluye que parte de las escuelas que participan en este estudio no siguen las normas de potabilidad del agua establecidas por la Ordenanza de Consolidación n ${ }^{\circ} .5$ del 28 de septiembre de 2017.

Palabras clave: Estándar de potabilidad del agua; Coliformes; Bebedor.

\section{Introdução}

A água destinada para consumo humano deve seguir parâmetros de potabilidade estabelecidos pelo Ministério da Saúde, como orientado atualmente a Portaria de Consolidação n 5 de 28 de setembro de 2017 (Origem Portaria 2.914/2011), conforme a qual se deve atender a uma série de características entre aspectos físicos, químicos e biológicos da água para garantir a saúde do indivíduo. Um desses parâmetros é a detecção da presença de coliformes totais e/ou termotolerantes, cuja Portaria estabelece a obrigatoriedade da ausência destes microrganismos na água para consumo humano (Oliveira \& Terra, 2004; Ratti et al., 2011; Seco, Brugos, \& Pelayo, 2012; Campos et al., 2017; Portaria n 05/2017).

Os coliformes correspondem a membros da família Enterobacterales que fazem parte da microbiota intestinal de animais homeotérmicos. Estes são bactérias Gram negativas, não fastidiosas, bacilos anaeróbios e aeróbios facultativos, não esporulados, móveis ou não, fermentadores de lactose que crescem em meios que possuam sais biliares. Os principais representantes de coliformes são os gêneros Escherichia, Klebsiella, Citrobacter Enterobacter. A presença destes microrganismos em água é utilizada como biomarcador de contaminação fecal (Oliveira \& Terra, 2004; Ratti et al., 2011; Paixão, \& Castro, 2016; Moretto, 2018; Alves, Ataide \& Silva, 2018; Lacerda, Rãder, \& Lopes, 2019; Rodrigues, \& Diniz, 2019).

A contaminação do indivíduo por esses agentes ocorre através da transmissão fecal-oral com a ingestão de água contaminada. Essas bactérias patogênicas podem ocasionar infecções no trato gastrointestinal (TGI), tais como gastroenterite bacteriana, diarreias agudas, disenteria e entre outras patologias associadas (Seco, Brugos, \& Pelayo, 2012; Paiva, \& Souza, 2018).

As doenças de veiculação hídrica merecem atenção, principalmente em países em desenvolvimento. Dados obtidos em 2016 pela Organização Mundial de Saúde (OMS) demonstram que houve mais de 870.000 mortes por consumo de água não potável no mundo. O outro estudo publicado pela OMS constatou em 2017 que 2,1 bilhões de pessoas não possuem saneamento básico, o que pode contribuir para a contaminação de fezes em água (Ratti, et al., 2011; Paiva, \& Souza, 2018; Organização Mundial de Saúde, 2016; Organização Mundial de Saúde, 2017; Organização Mundial de Saúde, 2018).

As escolas fazem parte do grupo vulnerável para doenças de veiculação hídrica, sendo assim, devem ser inspecionadas para assegurar oferta de água para consumo dentro dos padrões de potabilidade. Esse quadro pode apresentar um agravante quando o consumo é realizado por menores. As crianças possuem suscetibilidade a patologias associadas à ingestão da água contaminada, principalmente crianças menores de 5 anos (Brasil, 2016; Marinho et al., 2016; Brasil, 2018; Moraes et al., 2018).

Diante das informações expostas, a presente pesquisa teve como objetivo verificar se há presença de coliformes totais e termotolerantes na água disponível para consumo dos alunos nos bebedouros de escolas municipais, distribuídos em três bairros populares no município de Feira de Santana, Bahia, sendo esses bairros selecionados randomicamente através do sorteio feito pelos pesquisadores.

\section{Metodologia}

O presente estudo tratou-se de uma pesquisa exploratória de caráter quantitativo (Pereira et al., 2018) que realizou a análise microbiológica para deteç̧ão de coliformes totais e termotolerantes na água de consumo humano em bebedouros de escolas da rede municipal de Feira de Santana-BA, pesquisa essa autorizada pela Secretaria Municipal de Educação. O número de escolas analisadas foi de 16 instituições pertencentes a três bairros populares, selecionados randomicamente dentre todos os 
bairros da cidade, sendo três localizadas no bairro X, uma no bairro $\mathrm{Y}$ e doze no bairro $\mathrm{Z}$. As análises foram executadas em duplicata (A e B) com intervalo de uma semana entre cada análise.

A coleta da água foi realizada diretamente nas torneiras dos bebedouros, coletando-se cerca de $100 \mathrm{~mL}$ da amostra, tanto na primeira análise (A), quanto na segunda (B). As torneiras foram primeiramente higienizadas com álcool $70 \%$ nas regiões externa e interna a fim de reduzir possíveis contaminações. Os coletores estéreis continham $0,1 \mathrm{~mL}$ de tiossulfato de sódio $10 \%$ cuja função é a neutralização do cloro (Brasil, 2017).

Os recipientes contendo as amostras eram armazenados e transportados em caixa térmica com gelo e levados ao laboratório de Microbiologia da Unidade de Ensino Superior de Feira de Santana (UNEF) e analisadas em até 24 horas. A metodologia aplicada para detecção de coliformes foi a de Tubos Múltiplos, que consiste em um tubo de ensaio com um tubo de Durham invertido contendo o meio de cultivo, dividido em diluições seriadas (1:1, 1:10 e 1:100). As análises foram realizadas em três etapas: testes presuntivo, confirmativo e termotolerante (Brasil, 2017).

Para o teste presuntivo utilizou-se quinze tubos múltiplos, cinco para cada diluição, contendo $10 \mathrm{~mL}$ de caldo Lauril Sulfato Triptose (LST). O caldo LST inibe o crescimento de bactérias que não fazem parte do grupo coliforme. As amostras foram inoculadas e incubadas em estufa com temperatura $35 \pm 0,5^{\circ} \mathrm{C}$ por $24 / 48$ horas. Os tubos positivos apresentavam turbidez devido ao crescimento de bacteriano e formação de gás no interior do tubo de Durham causado pela liberação de $\mathrm{CO}_{2}$. Estes tubos seguiram para o teste confirmativo, já os tubos com turbidez e com ausência ou formação duvidosa de gás seguiram-se para o teste para termotolerantes (Brasil, 2017).

O teste confirmativo utilizou o Caldo Verde Brilhante Bile 2\% apropriado para a detecção de coliformes totais. Foram repicadas $10 \mu \mathrm{l}$ das alíquotas positivas do teste presuntivo em $10 \mathrm{~mL}$ deste caldo e incubadas em estufa com temperatura $35 \pm$ $0,5^{\circ} \mathrm{C}$ por $24 / 48$ horas. Já no teste para termotolerantes usou-se o Caldo Escherichia coli (EC) que permite o crescimento dos coliformes em temperaturas mais elevadas. Logo, repicou-se $10 \mu \mathrm{l}$ das alíquotas negativas no teste presuntivo em $10 \mathrm{~mL}$ do caldo EC e incubadas em banho-maria com temperatura de $44{ }^{\circ} \mathrm{C}$ por 24 horas. Ao final do período de incubação, foram contados e analisados os tubos que apresentaram crescimento (Brasil, 2017).

A quantificação de coliformes totais e termotolerantes foram dadas em Número Mais Provável (NMP) pela combinação de tubos negativos e positivos dos testes confirmativo e termotolerante das análises em duplicata. As amostras cuja presença de coliformes foi confirmada foram repicadas em ágar MacConkey e após crescimento, realizadas as provas bioquímicas através dos meios de análise (TSI, SIM, Citrato de Simmons, Fenilalanina, Ureia de Christensen, teste da Oxidase em fita e Prova de lisina) para identificação de gênero e espécie (Brasil, 2008; Brasil, 2017).

\section{Resultados e Discussão}

Por meio das análises microbiológicas realizadas em 16 escolas municipais de três bairros populares do município de Feira de Santana - BA, confirmadas por análise em duplicata, observou-se que em seis escolas (37,5\%) houve a presença de coliformes totais (Figura 1); nas dez escolas restantes (62,5\%) não foram identificados resultados positivos. 
Figura 1. Teste para coliformes totais positivo.

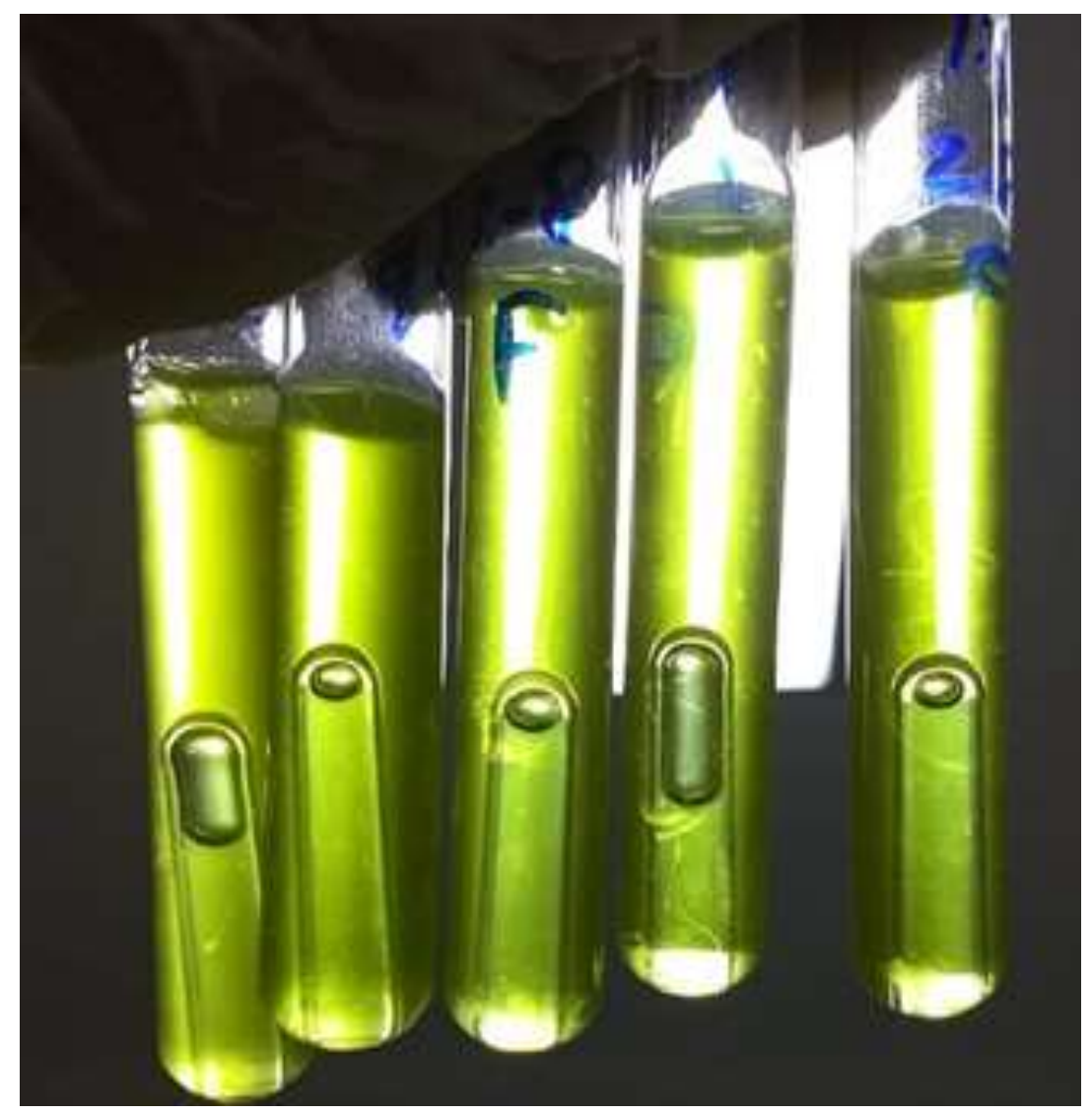

Fonte: Arquivo pessoal (2020).

Todas as escolas dos bairros X e Y seguiam os padrões determinados pela Portaria 2.914/2011 para a pesquisa deste grupo bacteriano (Portaria $n^{\circ}$ 05/2017), sendo que o bairro $X$ possui três escolas e a $Y$ apenas uma escola. Todavia, das doze escolas do bairro $Z$, em seis foram detectadas a presença dos coliformes totais, sugerindo não se tratar de um problema presente na fonte de abastecimento e sim de casos isolados, possivelmente pela falta de manutenção dos bebedouros, caixa d'água ou nas tubulações das escolas, onde os resultados obtidos estão expressos na Tabela 1. 
Tabela 1. Resultados das análises em duplicata (A e B) em NMP/100mL das escolas dos bairros X, Y e Z.

\begin{tabular}{|c|c|c|c|c|}
\hline Escolas & $\begin{array}{c}\text { Coliformes } \\
\text { totais } \\
\text { NMP/100mL }\end{array}$ & $\begin{array}{c}\text { Coliformes } \\
\text { termotolerantes } \\
\text { NMP/100mL }\end{array}$ & $\begin{array}{l}\text { Qualidade da água } \\
\text { para consumo }\end{array}$ & Bactéria identificada \\
\hline $\mathrm{X}-1$ & $\begin{array}{l}(\mathrm{A})<2 \\
(\mathrm{~B})<2\end{array}$ & $\begin{array}{l}(\mathrm{A})<2 \\
(\mathrm{~B})<2\end{array}$ & Satisfatória & - \\
\hline $\mathrm{X}-2$ & $\begin{array}{l}(\text { A) }<2 \\
(B)<2\end{array}$ & $\begin{array}{l}(\text { A) }<2 \\
(B)<2\end{array}$ & Satisfatória & - \\
\hline $\mathrm{X}-3$ & $\begin{array}{l}(\mathrm{A})<2 \\
(\mathrm{~B})<2\end{array}$ & $\begin{array}{l}(\text { A) }<2 \\
(B)<2\end{array}$ & Satisfatória & - \\
\hline $\mathrm{Y}-1$ & $\begin{array}{l}(\text { A) }<2 \\
(B)<2\end{array}$ & $\begin{array}{l}(\text { A) }<2 \\
(B)<2\end{array}$ & Satisfatória & - \\
\hline Z-1 & $\begin{array}{l}\text { (A) }<2 \\
\text { (B) }<2\end{array}$ & $\begin{array}{l}\text { (A) }<2 \\
\text { (B) }<2\end{array}$ & Satisfatória & - \\
\hline $\mathrm{Z}-2$ & $\begin{array}{l}(\mathrm{A})<2 \\
(\mathrm{~B})<2\end{array}$ & $\begin{array}{l}(\mathrm{A})<2 \\
(\mathrm{~B})<2\end{array}$ & Satisfatória & - \\
\hline Z-3 & $\begin{array}{l}(\mathrm{A})<2 \\
(\mathrm{~B})<2\end{array}$ & $\begin{array}{l}(\mathrm{A})<2 \\
(\mathrm{~B})<2\end{array}$ & Satisfatória & - \\
\hline $\mathrm{Z}-4$ & $\begin{array}{l}(A)=4 \\
(B)=6\end{array}$ & $\begin{array}{l}(\mathrm{A})<2 \\
(\mathrm{~B})<2\end{array}$ & Insatisfatória & Escherichia coli \\
\hline $\mathrm{Z}-5$ & $\begin{array}{l}(A)=2 \\
(B)=4\end{array}$ & $\begin{array}{l}\text { (A) }<2 \\
\text { (B) }<2\end{array}$ & Insatisfatória & Escherichia coli \\
\hline Z-6 & $\begin{array}{l}(A)=4 \\
(B)=50\end{array}$ & $\begin{array}{l}(\mathrm{A})<2 \\
(\mathrm{~B})<2\end{array}$ & Insatisfatória & Escherichia coli \\
\hline $\mathrm{Z}-7$ & $\begin{array}{l}(\mathrm{A})<2 \\
(\mathrm{~B})<2\end{array}$ & $\begin{array}{l}(\text { A) }<2 \\
(B)<2\end{array}$ & Satisfatória & - \\
\hline Z-8 & $\begin{array}{l}(\mathrm{A})<2 \\
(\mathrm{~B})<2\end{array}$ & $\begin{array}{l}(\mathrm{A})<2 \\
(\mathrm{~B})<2\end{array}$ & Satisfatória & - \\
\hline Z-9 & $\begin{array}{l}(\mathrm{A})<2 \\
(\mathrm{~B})<2\end{array}$ & $\begin{array}{l}(\mathrm{A})<2 \\
(\mathrm{~B})<2\end{array}$ & Satisfatória & - \\
\hline $\mathrm{Z}-10$ & $\begin{array}{l}(A)=130 \\
(B)=22\end{array}$ & $\begin{array}{l}\text { (A) }<2 \\
\text { (B) }<2\end{array}$ & Insatisfatória & Escherichia coli \\
\hline Z-11 & $\begin{array}{c}(A)=23 \\
(B)=4\end{array}$ & $\begin{array}{l}(\mathrm{A})<2 \\
(\mathrm{~B})<2\end{array}$ & Insatisfatória & Enterobacter aerogenes \\
\hline Z-12 & $\begin{array}{l}(\mathrm{A})=4 \\
(\mathrm{~B})=9\end{array}$ & $\begin{array}{l}\text { (A) }<2 \\
\text { (B) }<2\end{array}$ & Insatisfatória & Klebsiella pneumoniae \\
\hline
\end{tabular}

* Segundo a Portaria de Consolidação n ${ }^{\circ} 5$ de 28 de setembro de 2017.

Assim sendo, as escolas cujas amostras foram positivas para coliformes totais, procederam-se à identificação da espécie bacteriana isolada na água por meio de provas bioquímicas para Gram Negativos. É possível notar que as bactérias identificadas pertencem aos gêneros mais frequentemente citados em estudos semelhantes para este tipo de contaminação (Moretto, 2018; Alves, Ataide \& Silva, 2018; Lacerda, Rãder, \& Lopes, 2019; Rodrigues \& Diniz, 2019), conforme ilustrada na Tabela 1 .

A literatura demonstra que os agentes etiológicos associados à ingestão de água não potável incluem bactérias, vírus e parasitas entéricos. Os riscos quanto à patogenicidade estão ligados ao potencial de virulência do microrganismo e nas condições em que o hospedeiro se encontra (imunossupressão, desnutrição, condições socioeconômicas e de higiene). As principais doenças transmitidas são a cólera, febre tifoide, hepatite A e diarreias agudas (Seco, Brugos, \& Pelayo, 2012; Campos et al., 2017; Alves, Ataide \& Silva, 2018; Sampaio, 2019).

As doenças diarreicas agudas (DDA) por ingestão de água imprópria ao consumo humano é de notificação compulsória, tratadas como doenças transmitidas por alimentos (DTA) e regulamentada pela Portaria de Consolidação ${ }^{\circ} 4$ de 
28 de setembro de 2017 (Portaria n 04/2017). O levantamento realizado pelo Ministério da Saúde em 2017 para taxa de óbitos decorrente por DDA no Brasil para cada 100.000 habitantes apontou que a maior parte dos casos ocorreu na região Nordeste $(3,4)$, seguida das regiões Norte $(2,7)$, Centro-Oeste $(1,9)$, Sul $(1,8)$ e Sudeste $(1,7)$ (Brasil, 2019).

É importante salientar que as infecções do trato gastrointestinal se caracterizam como uma das doenças de grande prevalência na infância, visto que crianças são vulneráveis devido ao sistema imunológico mais frágil tornando-as um grupo suscetível, podendo provocar desde doenças do TGI mais brandas ou até mesmo evoluir para casos severos (Paranhos, Pina, \& Mello, 2011; Agra, 2014; Campos et al., 2017; Souza, 2017). Além dos riscos ligados à saúde das crianças pela ingestão de água fora dos padrões de potabilidade, estas complicações podem comprometer também o desempenho escolar, levando à falta atenção ou até mesmo ao abandono à educação (Sampaio, 2019).

Estudos publicados no Brasil na avaliação microbiológica da água para detecção desse grupo bacteriano em água de bebedouros em redes de ensino também constataram a presença de coliformes. A pesquisa realizada na cidade Teixeira de Freitas (BA) que abrangeu quatro creches da rede municipal com um total de 32 amostras provenientes das torneiras e bebedouros, identificou coliformes totais em $34,37 \%$ delas e em 3,12\% para coliformes termotolerantes (Meira, Silva, \& Fortuna, 2018).

Na cidade de Santa Rita (PB) uma pesquisa avaliou a potabilidade da água de quatro escolas estaduais, quatro escolas municipais e quatro escolas privadas onde $100 \%$ delas apresentaram coliformes totais e 33,3\% constataram coliformes termotolerantes (Moraes et al., 2018). Já em outra pesquisa feita na cidade de Pajeú (PE) que incluiu oito instituições municipais, houve positividade também de $100 \%$ das amostras para presença de coliformes totais. Contudo não foi observada presença de coliformes termotolerantes (Magalhães, Silva, \& Santos, 2020).

Os dados obtidos nesta pesquisa tornam-se ainda mais relevantes ao considerar que 37,5\% das escolas averiguadas detectaram coliformes totais em água destinada ao consumo de alunos que estudavam nas respectivas instituições no ano de 2019. Os mesmos estiveram expostos ao risco da ingestão destes agentes entéricos, tornando-os suscetíveis ao desenvolvimento de doenças associadas à ingestão de água contaminada por excretas. Isso ratifica então a importância da análise da água para consumo em escolas, onde deveriam acontecer inspeções periódicas de qualidade química e microbiológica, utilizando-se os coliformes utilizados como biomarcador de contaminação fecal (Brasil, 2016; Andrade \& Barros, 2019).

\section{Considerações Finais}

Em suma, pode-se notar pelos resultados positivos das escolas participantes desta pesquisa o quanto é importante a análise periódica da água para consumo humano em escolas. As crianças em idade escolar estão mais suscetíveis às infecções hidricamente veiculadas. É, portanto, premente o cumprimento da lei relativa aos padrões estabelecidos de potabilidade pelo Ministério da Saúde. A segurança alimentar deve ser prioridade no cuidado da saúde infantil, sob quaisquer de seus aspectos. O monitoramento constante da qualidade da água prevenirá futuras contaminações, logo, medidas apropriadas devem ser tomadas como a limpeza periódica dos filtros dos bebedouros e das caixas d'água, os possíveis focos da presente contaminação.

\section{Referências}

Agra, T. P. (2014). Prevalência de enteroparasitos e sua relação com saneamento básico em crianças em idade escolar, antes e após intervenções educativas e farmacológicas em Maceió, Alagoas. (dissertação). Universidade Federal de Alagoas, Maceió.

Alves, S. G. S., Ataide, C. D. G., \& Silva, J. X. (2018). Análise microbiológica de coliformes totais e termotolerantes em água de bebedouros de um parque público de Brasília, Distrito Federal. Rev. Cient. Sena Aires, 7 (1), 12-7. 
Andrade, G. F., \& Barros, D. B. (2019). Bioindicadores microbiológicos para indicação de poluição fecal. https://acervomais.com.br/index.php/saude/article/view/1099/824.

Brasil: Agencia Nacional de Vigilância Sanitária. (2008) Gram-negativos Fermentadores. http://www.anvisa.gov.br/servicosaude/co ntrole/rede_rm/cursos/boas_praticas/MODULO2/identificacao2.htm

Brasil: Fundação Nacional de Saúde (2017). Manual prático de análise de água. Brasília, Fundação Nacional de Saúde.

Brasil: Ministério da Saúde (2019). Doenças Diarreicas Agudas Brasil [slide].

Brasil: Ministério da Saúde. (2016). Diretriz Nacional do Plano de Amostragem da Vigilância da Qualidade da Água para Consumo Humano. Brasília: Ministério da Saúde.

Brasil: Ministério da Saúde. (2018). Política Nacional de atenção integral à saúde da criança orientações para implementação. Brasília: Ministério da Saúde.

Campos, D. A. G., Franco, J. M., Abreu Filho, B. A., Bergamasco, R., \& Yamaguchi, N. U. (2017). Avaliação da Qualidade da Água Destinada ao Consumo Humano em Instituição de Ensino. Revista da Universidade Vale do Rio Verde, 15 (1), 289-298.

Lacerda, A. B., Rãder, A. S., \& Lopes, E. S. (2019). A eficiência de remoção de coliformes em uma estação de tratamento de água convencional. Braz. J. of Develop., 5 (6), 7523-7539.

Magalhães, C. F. N., Santos, R. C., \& Silva, G. C. (2020). Avaliação de marcadores higiênicos sanitários na água das instituições de educação infantil de cidade da microrregião do Pajeú-PE. Braz. J. Hea. Rev., 3 (1) 847-856.

Marinho, J. S., Jesus, I. M., Asmus, C. I. R. F., Lima, M. O., \& OLIVEIRA, D. C. (2016). Doenças infecciosas e parasitárias por veiculação hídrica e doenças respiratórias em área industrial, Norte do Brasil. Cad. Saúde Colet., 24 (4), 443-451.

Meira, I. A., Silva, T. C., \& Fortuna, J. L. (2018). Pesquisa de coliformes na água de consumo das creches da rede municipal de ensino de Teixeira de Freitas, BA. Higiene Alimentar, 32 (278/279), 92-96.

Moraes, M. S., Moreira, D. A. S., Santos, J. T. L. A., Oliveira, A. P., \& Salgado, R. L. (2018). Avaliação microbiológica de fontes de água de escolas públicas e privadas da cidade de Santa Rita (PB). Eng Sanit Ambient., 23 (3), 431-435.

Moretto, V. T. (2018). Avaliação microbiológica da água e o perfil de resistência antimicrobiana em enterobactérias de coleções hídricas de salvador e área rural da Bahia. (Dissertação). Fundação Oswaldo Cruz, Salvador.

Oliveira, A. C., \& Terra, A. P. (2004). Avaliação Microbiológica das Águas dos Bebedouros do Campus I da Faculdade de Medicina do Triângulo Mineiro, em Relação à Presença de Coliformes Totais e Fecais [carta]. Rev. Soc. Bras. Med. Trop., 37 (3), 285-286.

Organização Mundial de Saúde. (2017). Guidelines for drinking-water quality: fourth edition incorporating the first addendum. Geneva: World Health Organization, 2017.

Organização Mundial de Saúde. (2017). Progress on Drinking Water, Sanitation and Hygiene Update and SDG Baselines 2017. https://www.who.int/mediacentre/news/releases/2017/launch-version-report-jmp-water-sanitation-hygiene.pdf?ua=1.

Organização Mundial de Saúde. (2018). Word health statistics 2018 monitoring health for the SDGs sustainable development goals. https://apps.who.int/iris/bitstream/handle/10665/272596/9789241565585eng.pdf?ua=ul.

Paiva, R. F. P. S., \& Souza, M. F. P. (2018). Associação entre condições socioeconômicas, sanitárias e de atenção básica e a morbidade hospitalar por doenças de veiculação hídrica no Brasil. https://www.scielosp.org/article/csp/2018.v34n1/e00017316/pt/.

Paixão, L. A., \& Castro, F. S. (2016). A colonização da microbiota intestinal e a sua influência na saúde do hospedeiro. Universitas: Ciência da Saúde, 14 (1), $85-96$.

Paranhos, V. D., Pina, J. C., \& Mello, D. F. (2011). Atenção integrada às doenças prevalentes na infância e o enfoque nos cuidadores: revisão integrativa da literatura. http://www.scielo.br/scielo.php?pid=S010411692011000100027\&script=sci_arttext\&tng=pt.

Portaria de Consolidação nº 4, de 28 de setembro de 2017. Diário Oficial da República Federativa do Brasil, 28 set. 2017. Brasil: Ministério da Saúde.

Portaria de Consolidação n ${ }^{\circ}$ 5, de 28 de setembro de 2017. Diário Oficial da República Federativa do Brasil, 28 set. 2017. Brasil: Ministério da Saúde.

Ratti, B. A., Brustolin, C. F., Siqueira, T. A., \& Torquato, A. S. (2011). Pesquisa de coliformes totais e fecais em amostras de água coletadas no bairro Zona Sete, na cidade de Maringá-PR. http://www.cesumar.br/prppge/pesquisa/epcc2011/anais/bianca_altrao_ratti\%20\%281\%29.pdf.

Rodrigues, G. S., \& Diniz, S. F. (2019). Avaliação do monitoramento e qualidade da água para o abastecimento público da zona urbana do município de Forquilha-Ceará. Rev Equa (UFPI), 8 (3), 279 - 294.

Sampaio, F. B. (2019). Análise microbiológica da água consumida por escolares em um município do interior da Bahia (Monografia). Faculdade Maria Milza, Governador Mangabeira.

Seco, B. M. S., Brugos, T. N., \& Pelayo, J. S. (2012). Avaliação bacteriológica das águas de bebedouros do campus da Universidade Estadual de Londrina PR. Semina: Ciênc. Biol. Saúde, 33 (2), 193-200.

Souza L. N. (2017). Análise microbiológica em bebedouros de escolas públicas do município de Santo Antônio de Jesus, Bahia (Monografia). Faculdade Maria Milza, Governador Mangabeira. 